\title{
Secondary Hyperparathyroidism in Chronic Kidney Disease: Pathophysiology and Management
}

\author{
Elmukhtar Habas Sr. ${ }^{1}$, Mohsen Eledrisi ${ }^{2}$, Fahmi Khan ${ }^{2}$, Abdel-Naser Y. Elzouki ${ }^{2}$ \\ 1. Internal Medicine, Hamad Medical Corporation, Doha, QAT 2. Internal Medicine, Hamad General Hospital, Doha, \\ QAT
}

Corresponding author: Elmukhtar Habas Sr., habas1962@gmail.com

\begin{abstract}
Serum calcium concentration is the main determinant of parathyroid hormone (PTH) release. Defect in the activation of vitamin D in the kidneys due to chronic kidney disease (CKD) leads to hypocalcemia and hyperphosphatemia, resulting in a compensatory increase in parathyroid gland cellularity and parathyroid hormone production and causing secondary hyperparathyroidism (SHP). Correction and maintenance of normal serum calcium and phosphate are essential to preventing SHP, hungry bone disease, cardiovascular events, and anemia development. Understanding the pathophysiology of PTH and possible therapeutic agents can reduce the development and associated complications of SHP in patients with CKD. Medical interventions to control serum calcium, phosphate, and PTH such as vitamin D analogs, calcium receptor blockers, and parathyroidectomy are needed in some CKD patients. In this review, we discuss the pathophysiology, clinical presentation, and management of SHP in CKD patients.
\end{abstract}

Review began 06/29/2021 Review ended 07/06/2021 Published 07/14/2021

๑) Copyright 2021

Habas et al. This is an open access article distributed under the terms of the Creative Commons Attribution License CC-BY 4.0., which permits unrestricted use, distribution, and reproduction in any medium, provided the original author and source are credited.
Categories: Endocrinology/Diabetes/Metabolism, Nephrology

Keywords: secondary hyperparathyroidism, hypocalcemia, hyperphosphatemia, chronic kidney disease, hungry bone syndrome

\section{Introduction And Background}

Parathyroid hormone (PTH) is a polypeptide protein released by the parathyroid gland [1]. PTH plays an essential role in bone mineralization and calcium and phosphate homeostasis by enhancing tubular calcium reabsorption in the kidneys, calcium absorption in the gastrointestinal tract, calcium mobilization from the bones, and phosphate excretion by the kidneys. The metabolically active form of vitamin D, 1,25dihydroxycholecalciferol $\left(1,25(\mathrm{OH})_{2} \mathrm{D}\right)$ stimulates intestinal calcium absorption and bone calcium mobilization. PTH, vitamin D, fibroblast growth factor-23 (FGF-23), phosphate, and calcium ion regulate serum calcium hemostasis [2]. Serum phosphate levels are high in primary and secondary hyperparathyroidism and low in primary hyperparathyroidism due to increased renal phosphate excretion.

\section{Review}

\section{Physiology of parathyroid hormone}

The main controller of PTH synthesis and secretion is the extracellular free (ionized) calcium [3]. Inorganic serum phosphate has contributory effects on PTH production and release by the parathyroid glands. The parathyroid glands have calcium sensor receptors (CaSR) that sense the changes in plasma calcium concentrations and regulate PTH secretion [4]. In addition, PTH synthesis and secretion are affected by $1,25(\mathrm{OH})_{2} \mathrm{D}$ formed by the conversion of 25 hydroxyvitamin $\mathrm{D}$ under the influence of the 1-alpha hydroxylase enzyme in the renal proximal tubular cells. $1,25(\mathrm{OH})_{2} \mathrm{D}$ binds to the parathyroid vitamin D receptor (VDR) which affects the synthesis of PTH-messenger RNA (PTH-mRNA) [5]. FGF-23 and osteocyte and osteoblastderived phosphaturic hormone [6] have been shown to decrease PTH synthesis and secretion [7]. Figure 1 shows the physiology of PTH. 


\section{Cureus}

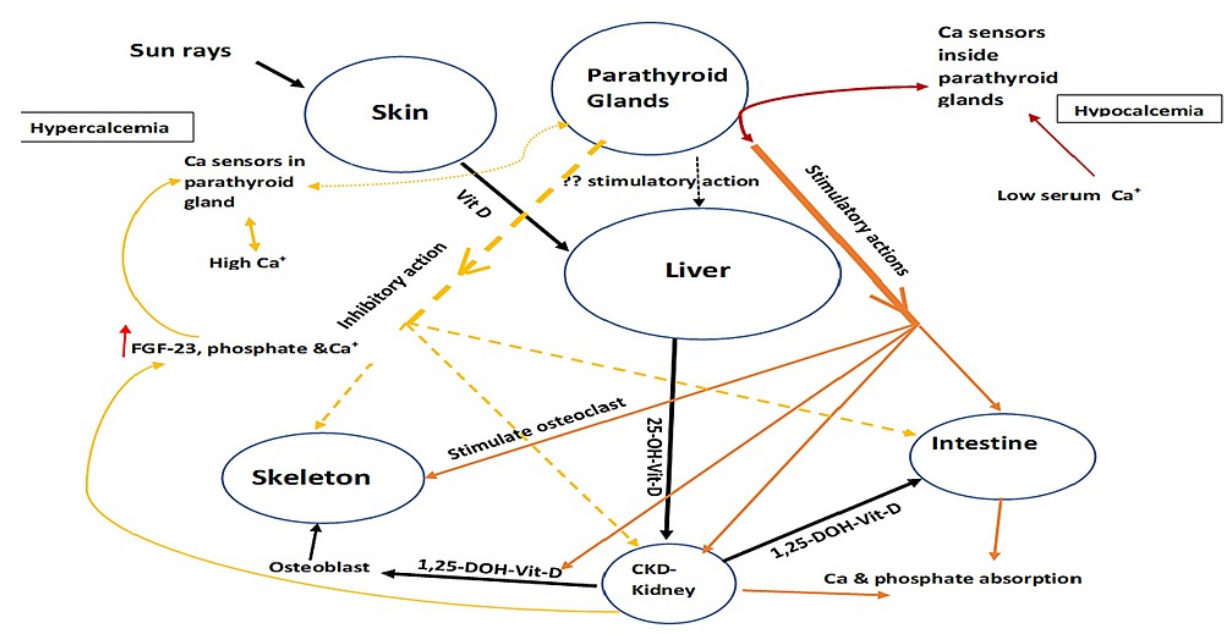

\section{FIGURE 1: Physiology of PTH.}

1,25-DOH-Vit-D: 1,25 dihydroxy hydroxycholecalciferol; 25-OH-Vit-D: 25 monohydroxy hydroxycholecalciferol; CKD: chronic kidney disease; FGF: fibroblast factor; PTH: parathyroid hormone; Vit D: vitamin D

\section{Pathophysiology of secondary hyperparathyroidism}

Prolonged low serum calcium levels trigger PTH secretion, leading to parathyroid cell proliferation and hyperplasia [8]. In addition, serum phosphate concentration affects PTH synthesis, secretion, parathyroid cell proliferation, vitamin D activation, and FGF-23 formation [9,10]. Moreover, PTH secretion has been shown to be dependent on phosphate concentration in bovine and rat parathyroid tissue [11,12]. In normal and uremic experimental models, high-phosphorus diets increase serum PTH levels [13]. Although the effect of serum phosphate level on serum PTH is not sufficiently clear, recent data have speculated that in addition to sensing serum calcium changes, CaSR can sense the changes in serum phosphate level [14]. Activation of 25 -hydroxy vitamin $\mathrm{D}$ to $1,25(\mathrm{OH})_{2} \mathrm{D}$ is controlled by PTH in the kidneys. $1,25(\mathrm{OH})_{2} \mathrm{D}$ employs a negative feedback effect to downregulate PTH expression. FGF-23 expression in bone osteocytes is regulated by phosphate, $1,25(\mathrm{OH})_{2} \mathrm{D}$, and PTH. Furthermore, increased FGF- 23 acts on the parathyroid fibroblast growth factor receptor (FGFR1)- $\alpha$ Klotho receptor complex to downregulate PTH expression $[15,16]$. Figure 2 shows the pathophysiology of SHP. 


\section{Cureus}

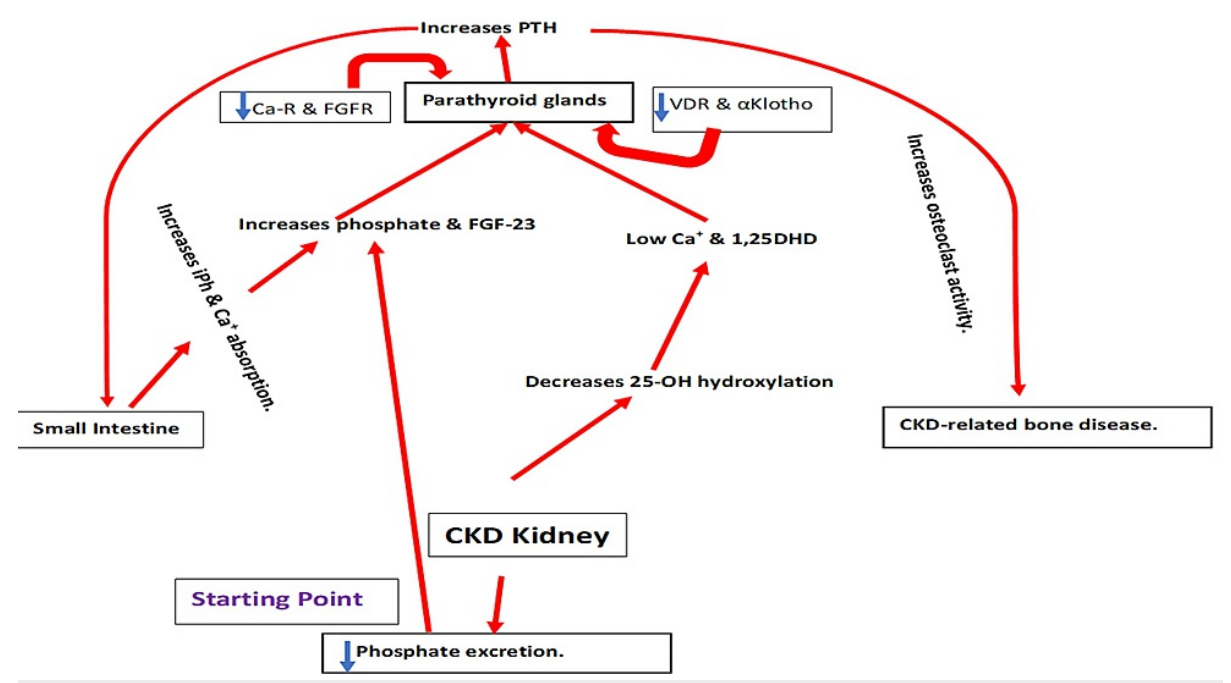

FIGURE 2: Pathophysiology of SHP.

1,25DHD: 1,25 dihydroxy vitamin D; Ca-R: calcium receptor; CKD: chronic kidney disease; FGF-23: fibroblast growth factor-23; FGFR: fibroblast growth factor receptor; iPh: inorganic phosphate; PTH: parathyroid hormone; SHP: secondary hyperparathyroidism; VDR: vitamin D receptor

In chronic kidney disease (CKD) patients, serum phosphate increases due to reduced phosphate secretion by the renal tubules, promoting the risk of development of SHP [17]. Furthermore, high serum phosphate has been reported to inhibit proximal renal tubule hydroxylase enzyme, complicating and further increasing the risk of hyperphosphatemia in CKD patients [18]. A progressive decline in glomerular filtration rate (GFR) in CKD leads to a reduction in the levels of $1,25(\mathrm{OH})_{2} \mathrm{D}$. The prolonged CKD-associated hypocalcemia and hyperphosphatemia drive the parathyroid gland to secrete more PTH to normalize the serum calcium and phosphate levels, leading to SHP. Nevertheless, this theory is not widely accepted because serum $1,25(\mathrm{OH})_{2} \mathrm{D}$ decreases during the early stages of CKD even before hypocalcemia and hyperphosphatemia occur. In the last decade, the discovery and characterization of the FGF-23 gene located on chromosome 12 have helped in understanding the early phases of the pathogenesis of SHP [19]. 1,25(OH $)_{2} \mathrm{D}$, phosphate, PTH, and calcium promote the synthesis and release of this protein by an unknown mechanism, although it is assumed that PTH induces FGF-23 transcription by triggering the bone-parathyroid-endocrine loop [20].

The membrane-bound $\alpha$ Klotho and FGF-23 along with their coreceptor induce phosphaturia through suppression of the sodium phosphate cotransporter [21]. $\alpha$ Klotho is produced by the kidneys, is considered to be an early biomarker for CKD, and may have extra autonomous anticalciuric and phosphaturic action, independent of FGF-23 [22]. In CKD, assembly of both membrane-bound and $\alpha$ Klotho leads to an increase in the serum levels of FGF- 23 due to decreased FGF- 23 clearance, leading to phosphate retention. The resistance to the phosphaturic action of FGF-23 is due to $\alpha$ Klotho deficiency, which becomes apparent with phosphate retention as CKD progresses.

$\alpha$ Klotho was originally recognized as an aging feature suppressor [23]. It is a single-pass transmembrane protein that acts as an FGF-23 coreceptor [24]. $\alpha$ Klotho is widely expressed, although it is predominantly higher in the kidneys [25]. As shown in an animal study, $\alpha$ Klotho deficiency leads to a premature aging syndrome associated with ectopic soft tissue calcification [23]. Overexpression of $\alpha$ Klotho reduces soft tissue calcification, indicating that $\alpha$ Klotho has an inhibitory effect on ectopic calcification [23].

FGF-23 levels increase as CKD progresses, leading to a "trade-off mechanism" between normalizing serum phosphate concentrations and activation of $1,25(\mathrm{OH})_{2} \mathrm{D}$, which may cause severe SHP [26]. In the late stages of CKD, hyperphosphatemia, decreased production of $1,25(\mathrm{OH})_{2} \mathrm{D}$, and hypocalcemia promote PTH-mRNA transcription and PTH formation, leading to SHP.

Persistent hypocalcemia leading to hyperplasia of parathyroid cells and downregulation of VDRs and CaSR in the parathyroid glands increase PTH secretion [27]. It has been postulated that FGF-23 may decrease PTH secretion via the $\alpha$ Klotho-FGFR1 complex [20]. In advanced SHP, the Klotho-FGFR1 complex expression in parathyroid cells is impaired [28], leading to an increase in the inhibitory effect of FGF-23 resistance to PTH secretion. Through activation of the mitogen-activated protein kinase pathway, FGF-23 acts on the receptor complex in the parathyroid glands to reduce PTH gene expression and secretion. Both FGF-23 and PTH are elevated in CKD, suggesting that the parathyroid glands are resistant to FGF-23 [29]. 
It has been reported that 30-50\% of patients with stage 5 CKD have PTH levels of $>300 \mathrm{pg} / \mathrm{mL}$ [30]. An earlier response that becomes maladaptive with CKD progression is a clinical syndrome termed chronic kidney disease-mineral and bone disorder (CKD-MBD) [31]. CKD-MBD is a disorder of mineral and bone metabolism that occurs due to an imbalance between PTH, serum calcium, phosphorus, and vitamin D metabolism. CKD-MBD causes bone abnormalities that affect turnover, volume, mineralization, vascular, linear growth, and density, and soft tissue calcification. CKD-MBD starts usually in stage 2 CKD [32], and is associated with vascular calcification, osteodystrophy, $\alpha$ Klotho loss, and increased FGF-23 secretion [32]. Associated skeletal manifestations have been shown to improve after controlling the serum PTH concentration [33], likely by mitigating the bone high turnover process (i.e., osteitis fibrosa) and improving the bone mineral density [34]; however, the extraskeletal complications did not improve [35].

\section{Clinical features of secondary hyperparathyroidism in chronic kidney disease}

Fragility fractures occur two to four times more frequently in patients with CKD-associated SHP compared to their age- and sex-matched healthy individuals. The risks of bone fractures are in the range of $15.0 \%, 20.5 \%$, $24.2 \%, 31.2 \%$, and $46.3 \%$ per 1,000 person-years for CKD stages 1,2 , 3a, 3b, and 4, respectively [36]. Skeletal fracture risk is up to five times more in individuals with an estimated glomerular filtration rate (eGFR) of

$<15 \mathrm{~mL} /$ minute versus $>60 \mathrm{~mL} /$ minute per $1.73 \mathrm{~m}^{2}$. Furthermore, fracture incidence is significantly higher in hemodialysis patients than in the general population, associated with a 3.7-fold increase in the unadjusted relative risk of death [37]. Other causes of reduced bone fragility and bone fracture such as metabolic acidosis, anemia, hypogonadism, inflammation, $\beta 2$ microglobulin associated with amyloidosis, vitamin D deficiency, bone formation inhibition secondary to osteoblast cell inhibition, along with that are not uncommon in CKD should be considered [34].

SHP causes vascular calcification of the coronary vessels and other peripheral vessels, causing ischemic cardiovascular events and heart failure. Furthermore, higher PTH in SHP increases sympathetic drive and endothelial stress [38]. Intimal and medial layer vascular calcification have been identified in CKD patients. Intimal calcification induced by CKD takes the form of atherosclerosis plaque calcification by increased osteoclastic in the neointimal layer. This type of calcification is originally related to small muscle cells and mesenchymal cells [39]. Mid-vascular layer calcification has also been correlated with chondro-osseous smooth vascular muscle cell transition [40]. High plasma DKK1 protein, sclerostin, bone morphogenetic protein 9 (BMP-9) [41], and activin have been observed in CKD patients [42].

Mild and moderate CKD increases coronary atherosclerotic disease risk by $87 \%$ [43]. The causes of an increased risk of cardiovascular disease are linked to CKD-MBD [44]. Three new cardiovascular risk factors have been identified within the CKD-MBD, namely, hyperphosphatemia, vascular calcification, and increased FGF-23 levels [45]. An animal study claimed that continuous infusion of PTH in CKD rats led to the development of hypercalcemia and severe calcification of the aortal medial layer [46]. On the contrary, intermittent teriparatide (PTH analog) in diabetic male mice prevented vascular calcification and aortic osteogenic transformation [47]. Though both studies could not explain the identical effects of PTH, both high serum calcium and phosphate and the high value of their product are recognized risk predictors of vascular calcification in patients with CKD. Moreover, SHP is directly related to serum alkaline phosphatase which is a good predictor of coronary artery calcification in CKD and hemodialysis patients [48]. Therefore, vascular calcification in SHP patients appears to be mediated by alkaline phosphatase, and this biological theory appears sensible because survival in these patients improves after parathyroidectomy.

Calciphylaxis or calcific uremic arteriolopathy is uncommon in patients with CKD and manifests as skin necrosis and severe ulcers that are difficult to heal. High PTH levels correlate with the occurrence of calciphylaxis, and parathyroidectomy is associated with a decreased mortality in this setting [49]. Parathyroidectomy does not result in improvement of vascular and soft tissue calcification [50].

SHP has been associated with resistance to the effects of erythropoietin therapy in patients with CKDassociated anemia; this is defined as failure to normalize hemoglobin after four to six months of erythropoietin therapy in the absence of iron deficiency [51]. The mechanisms by which SHP may cause anemia or reduce the bone marrow response to erythropoiesis are not clearly understood. High PTH levels can affect red blood cell production either directly via the toxic effect of PTH on bone marrow erythroid progenitors and increased hemolysis or indirectly through promoting bone marrow fibrosis [52]. This theory is supported by an improvement of anemia and reduction of bone marrow fibrosis following parathyroidectomy [53].

Treatment of Secondary Hyperparathyroidism

Controlling serum levels of PTH, phosphorus, calcium, and 25-hydroxy vitamin-D improves morbidity and mortality in patients with CKD [54].

\section{Treatment of hyperphosphatemia}


Controlling serum phosphorus is an essential step in the management of SHP. In CKD stages 2, 3, and 4, dietary phosphorus restriction is enough to maintain normal serum phosphorus levels [55]. Protein restriction is required to prevent renal function deterioration; however, daily protein requirement should be prescribed, while severe restriction may lead to malnutrition in CKD patients. Furthermore, patients' appetite decreases as kidney function worsens, increasing the risk of malnutrition. Therefore, vegetable protein is advisable more than anima protein, and processed food containing conservatives, high potassium, and salt should be avoided in patients with CKD.

As hyperphosphatemia becomes persistent and severe in patients with CKD, phosphate binders must be started. Phosphate binders are classified into calcium-based and noncalcium binders. Both types have almost the same effect in controlling the serum phosphate and serum PTH concentration in CKD-associated SHP. Calcium-containing binders include calcium acetate and calcium carbonate. Major noncalciumcontaining binders are sevelamer and lanthanum. Other agents include ferric citrate and sucroferric oxyhydroxide are used. The main side effect of calcium-containing binder is hypercalcemia [56].

Sevelamer is a resin noncalcium phosphate binder used to treat hyperphosphatemia. A meta-analysis study concluded that sevelamer reduced mortality more than other calcium phosphate binders [57]. Lanthanum carbonate is another noncalcium-based phosphate binder that prevents the intestinal absorption of phosphate. In addition to nausea, vomiting, and constipation, it may cause bowel obstruction or perforation. Lanthanum carbonate is primarily metabolized by the liver and is eliminated in bile. Although high serum levels of lanthanum carbonate have little effect on the bones, it may cause bone discomfort. Furthermore, lanthanum carbonate can produce elevated liver enzymes; however, this is usually not serious. Although lanthanum carbonate does not cross the blood-brain barrier, it can cause convulsions. Despite the mentioned and other side effects of lanthanum carbonate, they have no clinical implications if the patient and the treating physician are aware of them and intervene quickly if any of them are noted.

It has been recently reported that adding enteral sodium-phosphate (NPT2b) transporter blockades to nicotinamide plus lanthanum carbonate, nicotinamide plus placebo, or lanthanum carbonate plus placebo did not lead to any significant difference in hyperphosphatemia and serum FGF-3 level [58]. More studies are required to investigate their role in controlling hyperphosphatemia. Inhibition of enteral sodium/hydrogen exchanger-3 by tenapanor that was approved by the FDA in 2019 decreases phosphate absorption in patients on hemodialysis. However, the adverse effects of tenapanor such as increased stool sodium and water loss limited its widespread use [59].

\section{Vitamin D analogs}

Calcitriol is a vitamin D receptor activator (VDRAs) for the treatment of SHP to control hyperphosphatemia in patients with CKD [60]. It reduces bone turnover and prevents osteitis fibrosa in patients on hemodialysis [61]. Calcitriol is the usual agent to regulate serum PTH in SHP patients [62]. The possibility of hyperphosphatemia and hypercalcemia increases with high doses of calcitriol, which can increase the risk of morbidity and mortality in CKD-induced SHP.

Gene transcription regulation, inhibition of PTH-mRNA synthesis, and specific VDR-modifying agents have an inhibitory effect on PTH synthesis. In severe cases of SHP, there is a reduction of CaSR and VDRAs in the parathyroid glands [63]. Furthermore, VDRAs in advanced SHP do not effectively inhibit PTH secretion [64].

Selective VDRA vitamin D analogs such as paricalcitol (19-nor-1,25-dihydroxy vitamin D2) and maxacalcitol (22-oxa-1,25-dihydroxy vitamin D3) can reduce PTH levels better than calciferol without increasing the serum calcium concentration; however, it can cause hypercalcemia in some SHP patients. Native vitamin D esters are effective, and can be still used to decrease plasma PTH during earlier stages of SHP [64].

\section{Calcimimetics}

Cinacalcet decreases serum calcium and PTH efficiently in CKD-associated SHP [65]. Cinacalcet acts as a calcimimetic by allosteric $\mathrm{G}$ protein-coupled receptor modulator to activate the calcium-sensing receptor. Long-term use of cinacalcet reduces and improves the high bone turnover rate in end-stage renal disease among regular hemodialysis patients with SHP [66]. Furthermore, cinacalcet reduces the risk of death due to cardiovascular complications of SHP [67]. Additionally, cinacalcet reduces the risk of bone fracture compared with the placebo group [68]. The main side effects of cinacalcet are nausea and vomiting. Etelcalcetide is another calcimimetic agent which reduces PTH levels in patients on hemodialysis more effectively than cinacalcet without causing nausea and vomiting [69]. Paricalcitol (a selective vitamin D analog) has a limited action on intestinal and bone VDRs, but it decreases serum PTH levels.

\section{Parathyroidectomy}

In chronic hemodialysis patients, parathyroidectomy is required to control hyperparathyroidism in $15 \%$ and $35 \%$ of patients after 10 years and 35 years from the onset of hemodialysis, respectively [70]. Symptoms such as itching, bone pain, bone fracture, quality of life, and mortality are improved in some patients after parathyroidectomy [70]. In addition to the operative complications, hypophosphatemia, hypocalcemia, and 
occurrence and progression of the hungry bone syndrome are the most severe and common complications due to sudden serum PTH reduction following parathyroidectomy [71]. The hungry bone syndrome occurs in 5-8\% of patients with SHP after parathyroidectomy, and sometimes it may not be detected early, causing adynamic bone disease [72]. In hemodialysis patients, an adynamic bone disease noted following parathyroidectomy is associated with worsening of vascular calcification [73]. Post-parathyroidectomy hypoparathyroidism is not a common complication in SHP as in primary hyperparathyroidism.

Chemical ablation of parathyroid glands by percutaneous ethanol injection was conducted in 1985 as a treatment for SHP [74]. In 2003, a guideline included the use of ethanol to destroy the nodular parathyroid gland. Other hyperplasic glands are managed medically, and/or later can be treated by ethanol injection if medical treatment fails [75]. Furthermore, calcitriol percutaneous injection has been also used to destroy the hyperactive parathyroid gland instead of ethanol [76].

However, percutaneous ethanol and calcitriol are sometimes used for SHP patients who refuse or are not good candidates for surgical parathyroidectomy, and the long-term control of PTH level is not always achievable.

SHP may persist following renal transplantation, particularly in patients who had nodular SHP before parathyroidectomy, leading to hypercalcemia [77], and renal graft failure due to vascular calcification risk [78]. Surgical parathyroidectomy should be considered in kidney transplant patients with persistent hyperparathyroidism, especially when it is associated with hypercalcemia. Cinacalcet can be used as a bridging agent in renal transplant patients who have persistent hypercalcemia before parathyroidectomy [79].

\section{Conclusions}

The pathogenesis of SHP in patients with CKD has recently improved. The link between SPH and its consequences, including bone disease, vascular calcification, and anemia, requires more research. More therapeutic approaches for reducing the need for parathyroidectomy and its complications must be researched further in terms of their safety and efficacy.

\section{Additional Information \\ Disclosures}

Conflicts of interest: In compliance with the ICMJE uniform disclosure form, all authors declare the following: Payment/services info: All authors have declared that no financial support was received from any organization for the submitted work. Financial relationships: All authors have declared that they have no financial relationships at present or within the previous three years with any organizations that might have an interest in the submitted work. Other relationships: All authors have declared that there are no other relationships or activities that could appear to have influenced the submitted work.

\section{References}

1. Murray TM, Rao LG, Divieti P, Bringhurst FR: Parathyroid hormone secretion and action: evidence for discrete receptors for the carboxyl-terminal region and related biological actions of carboxyl- terminal ligands. Endocr Rev. 2005, 26:78-113. 10.1210/er.2003-0024

2. Riccardi D, Brown EM: Physiology and pathophysiology of the calcium-sensing receptor in the kidney . Am J Physiol Renal Physiol. 2010, 298:F485-99. 10.1152/ajprenal.00608.2009

3. Brown EM, Gamba G, Riccardi D, et al.: Cloning and characterization of an extracellular $\mathrm{Ca}(2+)$-sensing receptor from bovine parathyroid. Nature. 1993, 366:575-80. 10.1038/366575a0

4. Brown EM, Pollak M, Seidman CE, Seidman JG, Chou YH, Riccardi D, Hebert SC: Calcium-ion-sensing cellsurface receptors. N Engl J Med. 1995, 333:234-40. 10.1056/NEJM199507273330407

5. Dusso AS, Brown AJ, Slatopolsky E: Vitamin D. Am J Physiol Renal Physiol. 2005, 289:F8-28. 10.1152/ajprenal.00336.2004

6. Quarles LD: Endocrine functions of bone in mineral metabolism regulation . J Clin Invest. 2008, 118:3820-8. 10.1172/JCI36479

7. Galitzer H, Ben-Dov I, Lavi-Moshayoff V, Naveh-Many T, Silver I: Fibroblast growth factor 23 acts on the parathyroid to decrease parathyroid hormone secretion. Curr Opin Nephrol Hypertens. 2008, 17:363-7. 10.1097/MNH.0b013e328303e172

8. Silver J, Levi R: Regulation of PTH synthesis and secretion relevant to the management of secondary hyperparathyroidism in chronic kidney disease. Kidney Int Suppl. 2005, S8-12. 10.1111/j.15231755.2005.09501.x

9. Naveh-Many T, Silver J: The pas de trois of vitamin D, FGF23, and PTH . J Am Soc Nephrol. 2017, 28:393-5. 10.1681/ASN.2016090944

10. Kumar R, Thompson JR: The regulation of parathyroid hormone secretion and synthesis . J Am Soc Nephrol. 2011, 22:216-24. 10.1681/ASN.2010020186

11. Nielsen PK, Feldt-Rasmussen U, Olgaard K: A direct effect in vitro of phosphate on PTH release from bovine parathyroid tissue slices but not from dispersed parathyroid cells. Nephrol Dial Transplant. 1996, 11:1762-8.

12. Almaden Y, Canalejo A, Hernandez A, Ballesteros E, Garcia-Navarro S, Torres A, Rodriguez M: Direct effect of phosphorus on PTH secretion from whole rat parathyroid glands in vitro. J Bone Miner Res. 1996, 11:970- 
6. 10.1002/jbmr.5650110714

13. Naveh-Many T, Rahamimov R, Livni N, Silver J: Parathyroid cell proliferation in normal and chronic renal failure rats. The effects of calcium, phosphate, and vitamin D. J Clin Invest. 1995, 96:1786-93. 10.1172/JCI118224

14. Centeno PP, Herberger A, Mun HC, et al.: Phosphate acts directly on the calcium-sensing receptor to stimulate parathyroid hormone secretion. Nat Commun. 2019, 10:4693. 10.1038/s41467-019-12399-9

15. Ben-Dov IZ, Galitzer H, Lavi-Moshayoff V, et al.: The parathyroid is a target organ for FGF23 in rats . J Clin Invest. 2007, 117:4003-8. 10.1172/JCI32409

16. Krajisnik T, Björklund P, Marsell R, et al.: Fibroblast growth factor-23 regulates parathyroid hormone and 1alpha-hydroxylase expression in cultured bovine parathyroid cells. J Endocrinol. 2007, 195:125-31. 10.1677/JOE-07-0267

17. Slatopolsky E, Caglar S, Pennell JP, Taggart DD, Canterbury JM, Reiss E, Bricker NS: On the pathogenesis of hyperparathyroidism in chronic experimental renal insufficiency in the dog. J Clin Invest. 1971, 50:492-9. 10.1172/JCI106517

18. Llach F: Secondary hyperparathyroidism in renal failure: the trade-off hypothesis revisited . Am J Kidney Dis. 1995, 25:663-79. 10.1016/0272-6386(95)90541-3

19. Elias RM, Dalboni MA, Coelho AC, Moysés RM: CKD-MBD: from the pathogenesis to the identification and development of potential novel therapeutic targets. Curr Osteoporos Rep. 2018, 16:693-702. 10.1007/s11914-018-0486-0

20. Meir T, Durlacher K, Pan Z, Amir G, Richards WG, Silver J, Naveh-Many T: Parathyroid hormone activates the orphan nuclear receptor Nurr1 to induce FGF23 transcription. Kidney Int. 2014, 86:1106-15. 10.1038/ki.2014.215

21. Shimada T, Hasegawa H, Yamazaki Y, et al.: FGF-23 is a potent regulator of vitamin D metabolism and phosphate homeostasis. J Bone Miner Res. 2004, 19:429-35. 10.1359/JBMR.0301264

22. Kuro-O M: The Klotho proteins in health and disease . Nat Rev Nephrol. 2019, 15:27-44. 10.1038/s41581018-0078-3

23. Kuro-o M, Matsumura Y, Aizawa H, et al.: Mutation of the mouse klotho gene leads to a syndrome resembling ageing. Nature. 1997, 390:45-51. 10.1038/36285

24. Nakatani T, Sarraj B, Ohnishi M, et al.: In vivo genetic evidence for klotho-dependent, fibroblast growth factor 23 (Fgf23) -mediated regulation of systemic phosphate homeostasis. FASEB J. 2009, 23:433-41. 10.1096/fj.08-114397

25. Hu MC, Shi M, Zhang J, et al.: Klotho: a novel phosphaturic substance acting as an autocrine enzyme in the renal proximal tubule. FASEB J. 2010, 24:3438-50. 10.1096/fj.10-154765

26. Gutierrez O, Isakova T, Rhee E, et al.: Fibroblast growth factor- 23 mitigates hyperphosphatemia but accentuates calcitriol deficiency in chronic kidney disease. J Am Soc Nephrol. 2005, 16:2205-15. 10.1681/ASN.2005010052

27. Shilo V, Mor-Yosef Levi I, Abel R, Mihailović A, Wasserman G, Naveh-Many T, Ben-Dov IZ: Let-7 and microRNA-148 regulate parathyroid hormone levels in secondary hyperparathyroidism. J Am Soc Nephrol. 2017, 28:2353-63. 10.1681/ASN.2016050585

28. Krajisnik T, Olauson H, Mirza MA, et al.: Parathyroid Klotho and FGF-receptor 1 expression decline with renal function in hyperparathyroid patients with chronic kidney disease and kidney transplant recipients. Kidney Int. 2010, 78:1024-32. 10.1038/ki.2010.260

29. Silver J, Naveh-Many T: FGF23 and the parathyroid glands. Pediatr Nephrol. 2010, 25:2241-5. 10.1007/s00467-010-1565-3

30. Hedgeman E, Lipworth L, Lowe K, Saran R, Do T, Fryzek J: International burden of chronic kidney disease and secondary hyperparathyroidism: a systematic review of the literature and available data. Int J Nephrol. 2015, 2015:184321. 10.1155/2015/184321

31. Kidney Disease: Improving Global Outcomes (KDIGO) CKD-MBD Work Group (ed): KDIGO clinical practice guideline for the diagnosis, evaluation, prevention, and treatment of chronic kidney disease-mineral and bone disorder (CKD-MBD). 2009, 76:S1-130. 10.1038/ki.2009.188

32. Fang Y, Ginsberg C, Sugatani T, Monier-Faugere MC, Malluche H, Hruska KA: Early chronic kidney diseasemineral bone disorder stimulates vascular calcification. Kidney Int. 2014, 85:142-50. 10.1038/ki.2013.271

33. Rudser KD, de Boer IH, Dooley A, Young B, Kestenbaum B: Fracture risk after parathyroidectomy among chronic hemodialysis patients. J Am Soc Nephrol. 2007, 18:2401-7. 10.1681/ASN.2007010022

34. Chandran M, Wong J: Secondary and tertiary hyperparathyroidism in chronic kidney disease: an endocrine and renal perspective. Indian J Endocrinol Metab. 2019, 23:391-9. 10.4103/ijem.IJEM_292_19

35. Palmer SC, Hayen A, Macaskill P, Pellegrini F, Craig JC, Elder GJ, Strippoli GF: Serum levels of phosphorus, parathyroid hormone, and calcium and risks of death and cardiovascular disease in individuals with chronic kidney disease: a systematic review and meta-analysis. JAMA. 2011, 305:1119-27. 10.1001/jama.2011.308

36. Naylor KL, Garg AX, Zou G, et al.: Comparison of fracture risk prediction among individuals with reduced and normal kidney function. Clin J Am Soc Nephrol. 2015, 10:646-53. 10.2215/CJN.06040614

37. Tentori F, McCullough K, Kilpatrick RD, Bradbury BD, Robinson BM, Kerr PG, Pisoni RL: High rates of death and hospitalization follow bone fracture among hemodialysis patients. Kidney Int. 2014, 85:166-73. 10.1038/ki.2013.279

38. Kestenbaum B, Katz R, de Boer I, et al.: Vitamin D, parathyroid hormone, and cardiovascular events among older adults. J Am Coll Cardiol. 2011, 58:1433-41. 10.1016/j.jacc.2011.03.069

39. Naik V, Leaf EM, Hu JH, Yang HY, Nguyen NB, Giachelli CM, Speer MY: Sources of cells that contribute to atherosclerotic intimal calcification: an in vivo genetic fate mapping study. Cardiovasc Res. 2012, 94:545-54. 10.1093/cvr/cvs126

40. Speer MY, Yang HY, Brabb T, et al.: Smooth muscle cells give rise to osteochondrogenic precursors and chondrocytes in calcifying arteries. Circ Res. 2009, 104:733-41. 10.1161/CIRCRESAHA.108.183053

41. Zhu D, Mackenzie NC, Shanahan CM, Shroff RC, Farquharson C, MacRae VE: BMP-9 regulates the osteoblastic differentiation and calcification of vascular smooth muscle cells through an ALK1 mediated pathway. J Cell Mol Med. 2015, 19:165-74. 10.1111/jcmm.12373 
42. Agapova OA, Fang Y, Sugatani T, Seifert ME, Hruska KA: Ligand trap for the activin type IIA receptor protects against vascular disease and renal fibrosis in mice with chronic kidney disease. Kidney Int. 2016, 89:1231-43. 10.1016/j.kint.2016.02.002

43. Li J, Molnar MZ, Zaritsky JJ, et al.: Correlates of parathyroid hormone concentration in hemodialysis patients. Nephrol Dial Transplant. 2013, 28:1516-25. 10.1093/ndt/gfs598

44. Moe S, Drüeke T, Cunningham J, et al.: Definition, evaluation, and classification of renal osteodystrophy: a position statement from Kidney Disease: Improving Global Outcomes (KDIGO). Kidney Int. 2006, 69:194553. 10.1038/sj.ki.5000414

45. Blacher J, Guerin AP, Pannier B, Marchais SJ, London GM: Arterial calcifications, arterial stiffness, and cardiovascular risk in end-stage renal disease. Hypertension. 2001, 38:938-42. 10.1161/hy1001.096358

46. Neves KR, Graciolli FG, dos Reis LM, et al.: Vascular calcification: contribution of parathyroid hormone in renal failure. Kidney Int. 2007, 71:1262-70. 10.1038/sj.ki.5002241

47. Shao JS, Cheng SL, Charlton-Kachigian N, Loewy AP, Towler DA: Teriparatide (human parathyroid hormone (1-34)) inhibits osteogenic vascular calcification in diabetic low density lipoprotein receptor-deficient mice. J Biol Chem. 2003, 278:50195-202. 10.1074/jbc.M308825200

48. Shantouf R, Kovesdy CP, Kim Y, et al.: Association of serum alkaline phosphatase with coronary artery calcification in maintenance hemodialysis patients. Clin J Am Soc Nephrol. 2009, 4:1106-14. 10.2215/CJN.06091108

49. McCarthy JT, El-Azhary RA, Patzelt MT, et al.: Survival, risk factors, and effect of treatment in 101 patients with calciphylaxis. Mayo Clin Proc. 2016, 91:1384-94. 10.1016/j.mayocp.2016.06.025

50. Brandenburg VM, Kramann R, Rothe H, et al.: Calcific uraemic arteriolopathy (calciphylaxis): data from a large nationwide registry. Nephrol Dial Transplant. 2017, 32:126-32. 10.1093/ndt/gfv438

51. Tanaka M, Komaba H, Fukagawa M: Emerging association between parathyroid hormone and anemia in hemodialysis patients. Ther Apher Dial. 2018, 22:242-5. 10.1111/1744-9987.12685

52. Gallieni M, Corsi C, Brancaccio D: Hyperparathyroidism and anemia in renal failure. Am J Nephrol. 2000, 20:89-96. 10.1159/000013563

53. Mandolfo S, Malberti F, Farina M, Villa G, Scanziani R, Surian M, Imbasciati E: Parathyroidectomy and response to erythropoietin therapy in anaemic patients with chronic renal failure. Nephrol Dial Transplant. 1998, 13:2708-9. 10.1093/ndt/13.10.2708

54. Chen L, Wang K, Yu S, Lai L, Zhang X, Yuan J, Duan W: Long-term mortality after parathyroidectomy among chronic kidney disease patients with secondary hyperparathyroidism: a systematic review and metaanalysis. Ren Fail. 2016, 38:1050-8. 10.1080/0886022X.2016.1184924

55. Sprague SM, Abboud H, Qiu P, Dauphin M, Zhang P, Finn W: Lanthanum carbonate reduces phosphorus burden in patients with CKD stages 3 and 4: a randomized trial. Clin J Am Soc Nephrol. 2009, 4:178-85. 10.2215/CJN.02830608

56. National Kidney Foundation: K/DOQI clinical practice guidelines for bone metabolism and disease in chronic kidney disease. Am J Kidney Dis. 2003, 42:S1-201.

57. Patel L, Bernard LM, Elder GJ: Sevelamer versus calcium-based binders for treatment of hyperphosphatemia in CKD: a meta-analysis of randomized controlled trials. Clin J Am Soc Nephrol. 2016, 11:232-44. 10.2215/CJN.06800615

58. Ix JH, Isakova T, Larive B, et al.: Effects of nicotinamide and lanthanum carbonate on serum phosphate and fibroblast growth factor-23 in CKD: the COMBINE trial. J Am Soc Nephrol. 2019, 30:1096-108. 10.1681/ASN.2018101058

59. Palmer SC, Gardner S, Tonelli M, et al.: Phosphate-binding agents in adults with CKD: a network metaanalysis of randomized trials. Am J Kidney Dis. 2016, 68:691-702. 10.1053/j.ajkd.2016.05.015

60. Palmer SC, McGregor DO, Craig JC, Elder G, Macaskill P, Strippoli GF: Vitamin D compounds for people with chronic kidney disease requiring dialysis. Cochrane Database Syst Rev. 2009, CD005633. 10.1002/14651858.CD005633.pub2

61. Andress DL, Norris KC, Coburn JW, Slatopolsky EA, Sherrard DJ: Intravenous calcitriol in the treatment of refractory osteitis fibrosa of chronic renal failure. N Engl J Med. 1989, 321:274-9. 10.1056/NEJM198908033210502

62. Ifudu O: Care of patients undergoing hemodialysis. N Engl J Med. 1998, 339:1054-62. 10.1056/NEJM199810083391507

63. Kifor O, Moore FD Jr, Wang P, et al.: Reduced immunostaining for the extracellular Ca2+-sensing receptor in primary and uremic secondary hyperparathyroidism. J Clin Endocrinol Metab. 1996, 81:1598-606. 10.1210/jcem.81.4.8636374

64. Okuno S, Ishimura E, Kitatani K, et al.: Relationship between parathyroid gland size and responsiveness to maxacalcitol therapy in patients with secondary hyperparathyroidism. Nephrol Dial Transplant. 2003, 18:2613-21. 10.1093/ndt/gfg451

65. Komaba H, Nakanishi S, Fujimori A, et al.: Cinacalcet effectively reduces parathyroid hormone secretion and gland volume regardless of pretreatment gland size in patients with secondary hyperparathyroidism. Clin J Am Soc Nephrol. 2010, 5:2305-14. 10.2215/CJN.02110310

66. Behets GJ, Spasovski G, Sterling LR, Goodman WG, Spiegel DM, De Broe ME, D'Haese PC: Bone histomorphometry before and after long-term treatment with cinacalcet in dialysis patients with secondary hyperparathyroidism. Kidney Int. 2015, 87:846-56. 10.1038/ki.2014.349

67. Chertow GM, Block GA, Correa-Rotter R, et al.: Effect of cinacalcet on cardiovascular disease in patients undergoing dialysis. N Engl J Med. 2012, 367:2482-94. 10.1056/NEJMoa1205624

68. Moe SM, Abdalla S, Chertow GM, et al.: Effects of cinacalcet on fracture events in patients receiving hemodialysis: the EVOLVE trial. J Am Soc Nephrol. 2015, 26:1466-75. 10.1681/ASN.2014040414

69. Martin KJ, Bell G, Pickthorn K, Huang S, Vick A, Hodsman P, Peacock M: Velcalcetide (AMG 416), a novel peptide agonist of the calcium-sensing receptor, reduces serum parathyroid hormone and FGF23 levels in healthy male subjects. Nephrol Dial Transplant. 2014, 29:385-92. 10.1093/ndt/gft417

70. Lau WL, Obi Y, Kalantar-Zadeh K: Parathyroidectomy in the management of secondary hyperparathyroidism. Clin J Am Soc Nephrol. 2018, 13:952-61. 10.2215/CJN.10390917 
71. Jain N, Reilly RF: Hungry bone syndrome. Curr Opin Nephrol Hypertens. 2017, 26:250-5. 10.1097/MNH.0000000000000327

72. Witteveen JE, van Thiel S, Romijn JA, Hamdy NA: Hungry bone syndrome: still a challenge in the postoperative management of primary hyperparathyroidism: a systematic review of the literature. Eur J Endocrinol. 2013, 168:R45-53. 10.1530/EJE-12-0528

73. Hernandes FR, Canziani ME, Barreto FC, Santos RO, Moreira VM, Rochitte CE, Carvalho AB: The shift from high to low turnover bone disease after parathyroidectomy is associated with the progression of vascular calcification in hemodialysis patients: a 12-month follow-up study. PLoS One. 2017, 12:e0174811. 10.1371/journal.pone.0174811

74. Giangrande A, Castiglioni A, Solbiati L, Allaria P: Ultrasound-guided percutaneous fine-needle ethanol injection into parathyroid glands in secondary hyperparathyroidism. Nephrol Dial Transplant. 1992, 7:41221.

75. Fukagawa M, Kitaoka M, Tominaga Y, et al.: Guidelines for percutaneous ethanol injection therapy of the parathyroid glands in chronic dialysis patients. Nephrol Dial Transplant. 2003, 18 Suppl 3:iii31-3. 10.1093/ndt/gfg1008

76. Nakanishi S, Yano S, Nomura R, Tsukamoto T, Shimizu Y, Shin J, Fukagawa M: Efficacy of direct injection of calcitriol into the parathyroid glands in uraemic patients with moderate to severe secondary hyperparathyroidism. Nephrol Dial Transplant. 2003, 18 Suppl 3:iii47-9. 10.1093/ndt/gfg1012

77. Gwinner W, Suppa S, Mengel M, Hoy L, Kreipe HH, Haller H, Schwarz A: Early calcification of renal allografts detected by protocol biopsies: causes and clinical implications. Am J Transplant. 2005, 5:1934-41. 10.1111/j.1600-6143.2005.00938.x

78. Hernández D, Rufino M, Bartolomei S, González-Rinne A, Lorenzo V, Cobo M, Torres A: Clinical impact of preexisting vascular calcifications on mortality after renal transplantation. Kidney Int. 2005, 67:2015-20. 10.1111/j.1523-1755.2005.00303.x

79. Zavvos V, Fyssa L, Papasotiriou M, Papachristou E, Ntrinias T, Savvidaki E, Goumenos DS: Long-term use of cinacalcet in kidney transplant recipients with hypercalcemic secondary hyperparathyroidism: a singlecenter prospective study. Exp Clin Transplant. 2018, 16:287-93. 10.6002/ect.2016.0342 